\title{
DISPONIBILIDADE DOS METAIS PESADOS TÓXICOS CÁDMIO, CHUMBO E CROMO NO SOLO E TECIDO FOLIAR DA SOJA ADUBADA COM DIFERENTES FONTES DE NPK+ZN
}

\author{
Availability of cadmium, lead and chromium toxic heavy metals in soil and soybean \\ leaf tissue fertilized with different sources of $N P K+Z n$
}

\author{
Ivair André Nava ${ }^{1}$, Affonso Celso Gonçalves Junior ${ }^{2}$, Herbert Nacke ${ }^{2}$, Valdir Luiz Guerini ${ }^{3}$, Daniel Schwantes ${ }^{2}$
}

\begin{abstract}
RESUMO
Os fertilizantes utilizados para suprir micronutrientes podem apresentar metais pesados tóxicos em sua composição que podem proporcionar severas consequências ao meio ambiente. Plantas cultivadas na presença de determinadas concentrações de elementos tóxicos podem oferecer risco de contaminação, pois os acumulam em seus tecidos. Desse forma, neste trabalho objetivouse avaliar a disponibilização dos metais pesados tóxicos $\mathrm{Cd}, \mathrm{Pb}$, e $\mathrm{Cr}$ para o solo e tecido foliar da cultura da soja, cultivada a campo e fertilizada com um formulado $\mathrm{N}: \mathrm{P}_{2} \mathrm{O}_{5}: \mathrm{K}_{2} \mathrm{O}$ e diferentes fontes de $\mathrm{Zn}$. O delineamento experimental utilizado foi o de blocos ao acaso, em esquema fatorial $[(5+1) \mathrm{x} 2]$, com três repetições. Os tratamentos foram constituídos de cinco diferentes fertilizantes $\mathrm{NPK}+\mathrm{Zn}$ (quatro fontes com $\mathrm{Zn}$ e uma sem $\mathrm{Zn}$ ), um tratamento sem adubação e duas doses de adubação (uma vez e o seu dobro). Com base nos resultados obtidos foi concluído que a aplicação dos tratamentos disponibilizou $\mathrm{Cd}, \mathrm{Pb}$ e $\mathrm{Cr}$ para as plantas de soja e para o solo do experimento nas duas doses de adubação utilizadas.
\end{abstract}

Termos para indexação: Contaminação, micronutriente, Glycine max L.

\begin{abstract}
Fertilizers used to supply micronutrients may have toxic heavy metals in their composition, which can have severe consequences for the environment. Plants grown in the presence of certain concentrations of toxic elements may present a risk of contamination because the toxins accumulate in their tissues. This study aimed to measure the presence of the toxic heavy metals $\mathrm{Cd}, \mathrm{Pb}$ and $\mathrm{Cr}$ in the soil and leaf tissue of field-grown soybean plants, fertilized with a formulated $\mathrm{N}: \mathrm{P}_{2} \mathrm{O}_{5}: \mathrm{K}_{2} \mathrm{O}$ and different sources of $\mathrm{Zn}$. The experimental design utilized randomized blocks in a factorial scheme [(5+1)x2], with three replications. The treatments consisted of five different fertilizers NPK $+\mathrm{Zn}$ (four sources with $\mathrm{Zn}$ and one without $\mathrm{Zn}$ ), a treatment without fertilizer and two fertilizer levels (a single and double application). Based on obtained results it was concluded that the double application of the treatments released $\mathrm{Cd}, \mathrm{Pb}$ and $\mathrm{Cr}$ into the soybean plants and experiment.
\end{abstract}

Index terms: Contamination, micronutrient, Glycine max L.

(Recebido em 25 de agosto de 2009 e aprovado em 13 de maio de 2011)

\section{INTRODUÇÃO}

É de conhecimento geral que o cultivo da soja (Glycine max L.) é uma atividade extremamente importante para a economia brasileira e responsável por milhões de empregos diretos e indiretos.

Com relação a fertilização dessa cultura, o micronutriente zinco $(\mathrm{Zn})$ exerce funções importantes no metabolismo de carboidratos, proteínas e auxinas das plantas (MARTENS; WESTERMAN, 1991), e, assim, um dos meios para manter a produtividade de grãos é a correção da fertilidade e o manejo adequado do solo (OLIVEIRAet al., 2001; GONÇALVES JR. ; PESSOA, 2002).
Não obstante, nos sistemas agrícolas tecnificados, o desbalanceamento nutricional de micronutrientes no solo é comum e ocorre principalmente, em razão da correção da acidez destes, além de que, pela utilização de variedades produtivas melhoradas e mais exigentes em relação à nutrição aumenta-se cada vez mais a utilização de microelementos nos cultivos agrícolas (OLIVEIRA et al., 2001).

Os fertilizantes utilizados para suprir micronutrientes, possuem, muitas vezes, em sua composição, além dos elementos essenciais e desejáveis, também metais pesados tóxicos que são elementos com peso específico maior que $5 \mathrm{~g} \mathrm{~cm}^{-3}$ ou que possuem número atômico maior que 20 (MALAVOLTAet al., 1997).

\footnotetext{
1Universidade Estadual do Oeste do Paraná/UNIOESTE - Rua Pernambuco - 1777 - Cx. P. 91 - 85960-000 - Marechal Cândido Rondon, PR eaivair@yahoo.com.br

2Universidade Estadual do Oeste do Paraná/UNIOESTE - Marechal Cândido Rondon, PR

Instituto Agronômico do Paraná/IAPAR - Londrina, PR
}

Ciênc. agrotec., Lavras, v. 35, n. 5, p. 884-892, set./out., 2011 
Dentre os micronutrientes, muitos são metais pesados e são classificados desta maneira: essenciais, como o $\mathrm{Cu}, \mathrm{Fe}, \mathrm{Mn}$, Mo e $\mathrm{Zn}$, que são elementos indispensáveis para o desenvolvimento das plantas; benéficos, citando-se o $\mathrm{Co}$, Ni e V, sendo elementos que colaboram com o desenvolvimento das plantas, mas sua falta não é considerada um fator limitante e não essenciais ou tóxicos, sendo os principais o $\mathrm{Cd}, \mathrm{Cr}, \mathrm{Hg}$ e o $\mathrm{Pb}$, que são elementos prejudiciais às plantas (GONÇALVES JUNIOR; PESSOA, 2002).

Algumas indústrias de fertilizantes, com o objetivo de diminuir os custos de produção, passaram a utilizar resíduos industriais como fonte de elementos considerados essenciais às plantas, esses resíduos provêm primordialmente dos setores de fundição e siderurgia das empresas nacionais, embora nesse contexto, muitas dessas atividades estão sendo desenvolvidas com resíduos industriais perigosos originário de outros países (MONTEIRO, 2005).

Assim, para as formuladoras de micronutientes os benefícios são igualmente atraentes, uma vez que adquirem matéria-prima a custos irrisórios e, consequentemente, são as únicas que não geram nenhum tipo de resíduo, porque os incorporam diretamente nos seus produtos (GONÇALVES JUNIOR et al., 2000).

Plantas cultivadas com altas concentrações de metais pesados tóxicos podem oferecer risco de contaminação a toda cadeia produtiva, pois acumulam esses elementos em seus tecidos, sendo assim consideradas como um reservatório desses elementos nocivos, ocasionando a contaminação de animais e seres humanos (MARTINS et al., 2003).

Dessa forma, neste trabalho, objetivou-se avaliar a disponibilidade dos metais pesados tóxicos $\mathrm{Cd}, \mathrm{Pb}$, e $\mathrm{Cr}$ no solo e em plantas de soja cultivadas com a aplicação de fertilizantes formulados com diferentes fontes de Zn. Sendo avaliado ainda quais os fertilizantes que mais disponibilizaram metais pesados tóxicos para o solo, e se o aumento da dosagem destes proporcionará aumento na concentração desses metais pesados nas plantas.

\section{MATERIAL E MÉTODOS}

\section{Área de estudo}

O experimento foi conduzido a campo, no ano agrícola de 2007, safra de verão, no município de PalotinaPR que possui a latitude de $24^{\circ} 18^{\prime} 58^{\prime \prime} \mathrm{S}$, longitude de $53^{\circ}$ $55^{\prime} 18^{\prime \prime} \mathrm{W}$ e altitude média de $310 \mathrm{~m}$. O clima do município é classificado, segundo Koppen, como tropical quente úmido (Cfa), apresentando verões quentes e invernos frios e amenos.

O solo do local do experimento foi classificado como Latossolo Vermelho distroférrico (LVdf), possuindo textura argilosa (EMPRESA BRASILEIRA DE PESQUISA AGROPECUÁRIA, 2006a).

\section{Análises preliminares}

Para quantificação da condição inicial do solo e dos fertilizantes utilizados no experimento (Tabela 1) com relação à concentração de metais pesados tóxicos $\mathrm{Cd}, \mathrm{Pb}$ e $\mathrm{Cr}$, realizou-se análise química por meio de digestão nitro perclórica (AOAC, 2005) e determinções por espectrometria de absorção atômica (EAA), modalidade chama (WELZ; SPERLING 1999).

Foi realizada ainda a análise química para fins de fertilidade de uma amostra composta da área do experimento antes de sua instalação (Tabela 2), sendo utilizada a metodologia oficial para análises químicas de solo do Estado do Paraná (PAVAN et al., 1992).

Tabela 1 - Teores de $\mathrm{Cd}, \mathrm{Pb}$ e $\mathrm{Cr}$ nos fertilizantes utilizados no experimento.

\begin{tabular}{cccc}
\hline Amostra & $\mathrm{Cd}$ & $\mathrm{Pb}$ & $\mathrm{Cr}$ \\
\cline { 2 - 4 } Solo & 3,50 & 85,00 & 0,25 \\
Fonte Zn Marca A & 5,67 & 25,00 & 26,00 \\
Fonte Zn Marca B & 5,33 & 20,00 & 32,67 \\
Fonte Zn Marca C & 5,33 & 23,33 & 28,00 \\
Fonte Zn Marca D & 5,33 & 23,33 & 23,33 \\
Super Simples & 5,33 & 23,00 & 15,67 \\
Uréia & 5,00 & 18,00 & 47,33 \\
Cloreto de Potássio & 5,67 & 24,67 & 24,00 \\
Super Triplo & 5,67 & 22,00 & 21,33 \\
\hline
\end{tabular}


Tabela 2 - Características químicas do solo no início do experimento.

\begin{tabular}{|c|c|c|c|c|c|c|c|c|c|c|c|c|c|}
\hline \multirow{2}{*}{$\mathrm{pH}$} & $\mathrm{K}^{+}$ & $\mathrm{Ca}^{2+}$ & $\mathrm{Mg}^{2+}$ & $\mathrm{H}+\mathrm{Al}$ & SB & CTC & $\mathrm{C}$ & $\mathrm{P}$ & $\mathrm{Cu}$ & $\mathrm{Zn}$ & $\mathrm{Fe}$ & Mn & $\mathrm{V}$ \\
\hline & \multicolumn{6}{|c|}{------------------ $\mathrm{cmol}_{\mathrm{c}} \mathrm{dm}^{-3}$----------------- } & $\mathrm{g} \mathrm{dm}^{-3}$ & & 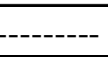 & $\mathrm{g} \mathrm{dm}^{-3}$ & & - & $\%$ \\
\hline 4,90 & 0,85 & 3,57 & 1,32 & 6,53 & 5,74 & 12,72 & 23,59 & 12,00 & 17,75 & 3,65 & 26,10 & 91,80 & 47,00 \\
\hline
\end{tabular}

pH em $\mathrm{CaCl}_{2} 0,01 \mathrm{~mol} \mathrm{~L}^{-1} ; \mathrm{H}+\mathrm{Al}$ - acidez potencial, SB - soma de bases, CTC - capacidade de troca catiônica, C - carbono orgânico, V\% - saturação por bases.

De forma complementar, determinou-se ainda a granulometria do solo pela metodologia da pipeta (EMPRESA BRASILEIRA DE PESQUISA AGROPECUÁRIA, 1997), onde se obtiveram os valores de $170,00 \mathrm{~g} \mathrm{~kg}^{-1}$ de areia; $180,00 \mathrm{~g} \mathrm{~kg}^{-1}$ de silte e $650,00 \mathrm{~g} \mathrm{~kg}^{-1}$ de argila.

\section{Instalação e condução do experimento}

O delineamento experimental utilizado foi na forma de blocos ao acaso (DBC), em esquema fatorial [(5+1)x2] com três repetições, constituído de cinco tratamentos com formulações de fertilizantes, um tratamento sem fertilizante e duas doses de aplicação.

Os tratamentos com as cinco formulações de fertilizantes químicos foram as seguintes: comercial A.

1. NPK fórmula $02-20-18$ com $0,3 \%$ de $\mathrm{Zn}$ da marca

2. NPK fórmula $02-20-18$ com $0,3 \%$ de Zn da marca comercial B.

3. NPK fórmula $02-20-18$ com $0,3 \%$ de $\mathrm{Zn}$ da marca comercial C. comercial D

4. NPK fórmula $02-20-18$ com $0,3 \%$ de Zn da marca

5. NPK fórmula $02-20-18$ com $0,0 \%$ de Zn.

Os tratos culturais e adubação foram realizados e calculados conforme objetivos de produtividade pela Empresa Brasileira de Pesquisa Agropecuária (2006b), levando em consideração a análise de solo (Tabela 2), cuja aplicação foi de uma vez $300 \mathrm{~kg} \mathrm{ha}^{-1}$ do formulado $\mathrm{N}_{2}, \mathrm{P}_{2} \mathrm{O}_{5}$, $\mathrm{K}_{2} \mathrm{O}+\mathrm{Zn}$ e o seu dobro com $600 \mathrm{~kg} \mathrm{ha}^{-1}$. Foi utilizada a cultivar de soja NK-412113, pertencente ao grupo de maturação precoce (5.9), com ciclo médio de 125 dias, semeada em novembro de 2007.

As parcelas foram constituídas de cinco linhas de soja com $4 \mathrm{~m}$ de comprimento e espaçamento entre linhas de $0,45 \mathrm{~m}$. Utilizaram-se como parcela útil as três linhas centrais da parcela, usando como bordadura $1 \mathrm{~m}$ da extremidade de cada linha em direção ao centro, restando 2,7 $\mathrm{m}^{2}$ de área útil.

A adubação e semeadura da soja, em sistema de plantio direto na palha (SPDP), foram realizadas manualmente por meio da abertura de sulcos no solo com o uso de discos de corte de uma semeadora na profundidade de $6 \mathrm{~cm}$ para a deposição do fertilizante. Na semeadura, foram depositadas cerca de 25 sementes por metro linear a dois centímetros de profundidade. As sementes foram tratadas com o fungicida Carbendazim na dosagem de $2 \mathrm{~mL} \mathrm{~kg}^{-1}$ de semente, o inseticida Fipronil na dose de $2 \mathrm{~mL} \mathrm{~kg}^{-1}$ de semente e o inoculante Bradyrhizobium elkanii, na dose de $2 \mathrm{~g} \mathrm{~kg}^{-1}$ de semente.

Para controle das plantas daninhas, foi aplicado herbicida latifolicida Clorimurom-etílico, na dose de $50 \mathrm{~g}$ $\mathrm{ha}^{-1}$ e o graminicida Setoxidim, na dose de 1,25 $\mathrm{L} \mathrm{ha}^{-1}$. Para controle de insetos foram aplicados os inseticidas Metamidofós, na dose de $0,75 \mathrm{~L} \mathrm{ha}^{-1}$ e Clorpirifós, na dose de $0,75 \mathrm{~L} \mathrm{ha}^{-1}$. Para controle de doenças, foi aplicado o fungicida Epoxiconazol + Piraclostrobina, na dose de $0,5 \mathrm{~L} \mathrm{ha}^{-1}$.

\section{Coleta e análise química do material vegetal}

Aos 53 dias após a emergência (DAE), no estádio fenológico R2 (floração plena com maioria dos racemos com flores abertas) da cultura da soja realizou-se a coleta de amostras foliares para determinação dos teores de P, K, $\mathrm{Ca}, \mathrm{Mg}, \mathrm{Zn}, \mathrm{Cd}, \mathrm{Pb}$ e $\mathrm{Cr}$. Em cada parcela útil, foram coletadas 20 folhas do terço média da planta, retirando-se o trifólio mais o pecíolo (EMPRESA BRASILEIRA DE PESQUISAAGROPECUÁRIA, 2006b). Após coletadas, as folhas foram desidratadas em estufa de circulação forçada de ar, na temperatura de $65^{\circ} \mathrm{C}$, durante $48 \mathrm{~h}$, sendo, em seguida, trituradas em micromoinho e acondicionadas em sacos de polietileno limpos.

Para determinação dos nutrientes $\mathrm{K}, \mathrm{Ca}, \mathrm{Mg}, \mathrm{Zn}$, $\mathrm{Cd}, \mathrm{Pb}$ e $\mathrm{Cr}$ no tecido foliar da soja foi utilizada a digestão nitro perclórica (AOAC, 2005) e EAA modalidade chama (WELZ; SPERLING, 1999). OP foi determinado por meio de digestão sulfúrica (AOAC, 2005) e espectroscopia de ultravioleta-visível (UV-Vis).

\section{Coleta e análise química do solo após colheita}

Após a colheita, que ocorreu aos $125 \mathrm{DAE}$, dentro de cada parcela útil, em cada uma da três linhas centrais de 
semeadura, foi coletada uma sub amostra de solo que, por fim, formaram uma amostra composta, onde foram determinados os teores de $\mathrm{P}, \mathrm{K}, \mathrm{Ca}, \mathrm{Mg}, \mathrm{Zn}, \mathrm{Cd}, \mathrm{Pb}$ e $\mathrm{Cr}$. Para determinação dos elementos $\mathrm{P}, \mathrm{K}, \mathrm{Ca}, \mathrm{Mg}$ e $\mathrm{Zn}$, foi utilizada a mesma metodologia da análise química do solo (PAVAN et al., 1992) e para os metais pesados tóxicos $(\mathrm{Cd}$, $\mathrm{Pb}$ e $\mathrm{Cr}$ ) foi utilizada a digestão nitro perclórica (AOAC, 2005) aliada a EAA, modalidade chama (WELZ; SPERLING, 1999).

\section{Análise estatística}

Todos os dados obtidos experimentalmente foram submetidos a análise de variância (ANAVA) e as médias comparadas pelo teste Tukey a 5\% de probabilidade. O programa estatístico utilizado foi o SISVAR 5.0 (FERREIRA, 2003).

\section{RESULTADOS E DISCUSSÃO}

\section{Tecido Foliar da soja}

Na Tabela 3, são apresentados os quadrados médios da análise de variância para o tecido vegetal da soja.

A análise demonstrou efeito significativo na fonte de variação, dose $(\mathrm{P}<0,05)$ para os elementos $\mathrm{Ca}, \mathrm{Zn}, \mathrm{Pb}$ e Cr. Já para as fontes de variação fertilização e dose versus fertilização não houve efeito significativo $(\mathrm{P}>0,05)$ para nenhum dos elementos avaliados. Resultados semelhantes foram encontrados por Gonçalves Junior et al. (2008), para os teores foliares dos nutrientes $\mathrm{P}$ e $\mathrm{Zn}$ em milho cultivado com diferentes doses de NPK+Zn em um solo argiloso. Também em outro trabalho, Gonçalves Junior et al. (2010), não obtiveram resultados significativos para os teores foliares de P e K, em soja com adubação de P, K e Zn em diferentes doses de aplicação.

Na Tabela 4, encontra-se a avaliação das médias do tratamento dose para os teores dos elementos avaliados. Para os teores de $\mathrm{Ca}, \mathrm{Zn}, \mathrm{Pb}$ e $\mathrm{Cr}$; quando se utilizou uma vez a dose, as médias obtidas foram superiores quando comparadas ao dobro da dose, assim, o aumento da dose não contribuiu para o aumento dos teores foliares.

Os teores de metais pesados nos tecidos das plantas dependem do $\mathrm{pH}$ do solo, da natureza do metal, do teor de matéria orgânica e da capacidade do solo em reter cátions (CHANG et al., 1987; MCBRIDE, 1995).

Assim como o fertilizante químico industrial, outra forma de elevar a concentração de metais pesados no sistema solo-planta é o lodo de esgoto (KABATAPENDIAS; PENDIAS, 2001). Em estudos envolvendo acúmulo de metais pesados em plantas, Oliveira e Mattiazzo (2001) e Martins et al., (2003) encontraram diferentes padrões de acúmulo de metais pesados no tecido foliar com o acréscimo de doses de lodo de esgoto, que inclui

Tabela 3 - Análise de variância para os teores de P, K, Ca, Mg, Zn, Cd, Pb e Cr no tecido foliar da soja.

\begin{tabular}{cccccccccc}
\hline \multicolumn{1}{c}{ Quadrados Médios } \\
\hline F.V. & GL & $\mathrm{P}$ & $\mathrm{K}$ & $\mathrm{Ca}$ & $\mathrm{Mg}$ & $\mathrm{Zn}$ & $\mathrm{Cd}$ & $\mathrm{Pb}$ & $\mathrm{Cr}$ \\
\hline Bloco & 2 & $0,12^{\mathrm{NS}}$ & $5,05^{\mathrm{NS}}$ & $41,78^{\mathrm{NS}}$ & $0,57^{\mathrm{NS}}$ & $29,25^{\mathrm{NS}}$ & $0,03^{\mathrm{NS}}$ & $498,70^{\mathrm{NS}}$ & $3,11^{\mathrm{NS}}$ \\
Dose & 1 & $0,09^{\mathrm{NS}}$ & $5,44^{\mathrm{NS}}$ & $59,29^{*}$ & $0,16^{\mathrm{NS}}$ & $75,11^{*}$ & $0,03^{\mathrm{NS}}$ & $2584,00^{*}$ & $30,25^{*}$ \\
Fertilização & 5 & $0,02^{\mathrm{NS}}$ & $1,57^{\mathrm{NS}}$ & $13,91^{\mathrm{NS}}$ & $0,07^{\mathrm{NS}}$ & $10,13^{\mathrm{NS}}$ & $0,01^{\mathrm{NS}}$ & $41,01^{\mathrm{NS}}$ & $2,46^{\mathrm{NS}}$ \\
DoseXFertil. & 5 & $0,02^{\mathrm{NS}}$ & $1,91^{\mathrm{NS}}$ & $14,31^{\mathrm{NS}}$ & $0,19^{\mathrm{NS}}$ & $5,18^{\mathrm{NS}}$ & $0,01^{\mathrm{NS}}$ & $12,68^{\mathrm{NS}}$ & $1,02^{\mathrm{NS}}$ \\
Resíduo & 22 & 0,03 & 2,09 & 12,76 & 0,40 & 7,86 & 0,01 & 91,32 & 2,63 \\
\hline CV $(\%)$ & - & 11,18 & 3,82 & 26,95 & 12,44 & 7,34 & 16,79 & 37,44 & 48,28 \\
\hline
\end{tabular}

* - significativo a 5\% de probabilidade, pelo teste de F (Fisher); NS - não significativo pelo teste de F (Fischer); F.V. - fonte de variação.

Tabela 4 - Valores médios dos teores de P, K, Ca, Mg, Zn, Cd, Pb e Cr no tecido foliar da soja em função da dose de fertilização.

\begin{tabular}{ccccccccc}
\hline Doses & $\mathrm{P}$ & $\mathrm{K}$ & $\mathrm{Ca}$ & $\mathrm{Mg}$ & $\mathrm{Zn}$ & $\mathrm{Cd}$ & $\mathrm{Pb}$ & $\mathrm{Cr}$ \\
\hline \multicolumn{1}{c}{ D1 } & $1,56 \mathrm{a}$ & $37,45 \mathrm{a}$ & $14,53 \mathrm{a}$ & $4,97 \mathrm{a}$ & $39,61 \mathrm{a}$ & $0,70 \mathrm{a}$ & $34,00 \mathrm{a}$ & $4,27 \mathrm{a}$ \\
D2 & $1,46 \mathrm{a}$ & $38,23 \mathrm{a}$ & $11,97 \mathrm{~b}$ & $5,10 \mathrm{a}$ & $36,72 \mathrm{~b}$ & $0,76 \mathrm{a}$ & $17,05 \mathrm{~b}$ & $2,44 \mathrm{~b}$ \\
\hline
\end{tabular}

Médias seguidas da mesma letra não diferem pelo teste de Tukey a $5 \%$ de probabilidade; D1 - uma vez a dose; D2 - dobro da dose. 
respostas negativas, positivas ou ausência de resposta ao acréscimo dos teores de metais em solo (PAGE et al., 1987), contrariando a expectativa de que os teores de metais nos tecidos vegetais aumentam com a elevação da concentração de elementos na solução do solo, pelo fato de existirem vários fatores influenciando o sistema soloplanta (GUSSARSSON et al., 1995).

No caso do $\mathrm{Pb}$, em que a maior dose diminuiu seu teor foliar (Tabela 4), Rangel et al. (2006) encontraram o mesmo comportamento em plantas de milho cultivadas em um Latossolo Vermelho distroférrico de textura argilosa, onde verificou-se uma diminuição dos teores foliares nas doses mais altas aplicadas de lodo de esgoto contaminado com metais pesados.

Com relação ao $\mathrm{Cr}$, observa-se que nos vegetais a maior parte desse elemento é retida nas raízes e somente uma pequena parcela é transportada para as partes superiores da planta, sendo improvável a sua bioacumulação proveniente do solo nessas partes, sendo que existem ainda vegetais que são considerados de pouca, de moderada ou de alta capacidade de acumulação de metais, entre os que são de pouca acumulação temos as leguminosas (soja) (WANG et al., 2002; MORTVEDT, 2001).

Para o Ca, houve redução em seu teor nas folhas ao se utilizar a dose D2, corroborando os resultados obtidos por Huang e Cunningham (1996), ao trabalharem com diferentes doses de $\mathrm{Pb}$ na cultura do milho, que observaram uma redução no teor de Ca foliar, na medida em que elevaramse as doses de $\mathrm{Pb}$. Esse comportamento se deve, de acordo com Marschner (1995), ao fato de que cátions divalentes como $\mathrm{Pb}^{2+}$ competem com outros cátions, como o $\mathrm{Ca}^{2+}$.

$\mathrm{O}$ teor de $\mathrm{Mg}$ nas folhas não diferiu estatisticamente, demonstrando que os diferentes tratamentos não influenciaram na absorção e acúmulo desse nutriente. Resultados semelhantes foram encontrados por Paiva et al. (2002), que não obtiveram resposta significativa na aplicação de doses crescentes $\mathrm{de} \mathrm{Pb}$. Ao passo que, em plantas de Zea mays, Huang e Cunningham (1996), verificaram redução no teor de Mg na parte aérea das plantas.

Para oZn, observou-se que, com o aumento da dose, os teores foliares diminuíram, efeito que pode ser justificado pelas afirmações de Malavolta et al. (1997), que relatam relações detrimentais da interação $\mathrm{P}$ x $\mathrm{Zn}$ devido a: a insolubilização do $\mathrm{Zn}$ pelo fosfato na superfície das raízes (reduzindo a absorção); a inibição não-competitiva da absorção de Zn pelo P; ou a insolubilização no xilema (prejudicando o transporte para a parte aérea das plantas). Segundo Büll (1993), a interação P x Zn está ligada a uma desordem metabólica, em razão do desbalanceamento entre esses nutrientes. Não obstante, Carneiro et al. (2008) trabalhando com a quantificação da interação P/Zn, obtiveram resultados semelhantes aos obtidos no presente trabalho.

As concentrações médias de $\mathrm{Cd}$ no tecido foliar das plantas de soja (Tabela 4) podem ser consideradas abaixo do nível crítico para plantas, uma vez que, de acordo com Davis et al. (1978) apenas teores acima de $15 \mathrm{mg} \mathrm{kg}^{-1}$ desse metal tóxico podem causar toxidez nas plantas, ao passo que Kabata-Pendias e Pendias (2001) consideram como faixa crítica de $\mathrm{Cd}$ na biomassa de plantas o intervalo de 5 a $30 \mathrm{mg} \mathrm{kg}^{-1}$.

Observando-se ainda a Tabela 4, de acordo com Kabata-Pendias e Pendias (2001), verifica-se que para a dose D1, somente os elementos Cd e Cr encontram-se na faixa normal e o $\mathrm{Pb}$ encontra-se na faixa crítica, para a dose $\mathrm{D} 2$ os elementos $\mathrm{Cd}, \mathrm{Pb}$ e $\mathrm{Cr}$ estão na faixa normal.

\section{Solo}

Na Tabela 5, são apresentados os quadrados médios da análise de variância para os teores de macro e micronutrientes encontrados no solo após a colheita do experimento.

A análise demonstrou efeito significativo $(\mathrm{P}<0,05)$ na fonte de variação dose para os elementos $\mathrm{P}, \mathrm{K}, \mathrm{Mg}, \mathrm{Zn}$, $\mathrm{Cd}, \mathrm{Pb}$ e Cr. Já, para a fonte de variação fertilização só ocorreu efeito significativo $(\mathrm{P}<0,05)$ na análise de variância para o elemento $\mathrm{Zn}$, que também teve efeito na interação entre dose versus fertilização.

As médias dos teores de macro e micronutrientes para a fonte de variação dose estão apresentadas na Tabela 6 , onde pode-se observar que, aplicando a dose D1, os teores de $\mathrm{Mg}$, $\mathrm{Pb}$ e $\mathrm{Cd}$ apresentaram médias superiores em comparação a dose D2. Já, para os teores de P, K e Cr, a dose $\mathrm{D} 2$ proporcionou médias superiores em relação a dose D1 de adubação.

Na Tabela 6, observa-se que a dose $\mathrm{D} 2$ proporcionou aumento significativo do elemento $P$, já, para os elementos $\mathrm{Cd}$ e $\mathrm{Pb}$ ocorreu uma diminuição significativa. Os pesquisadores Gonzalez et al. (1992) encontraram resultados semelhantes avaliando metais pesados em lodo de esgoto em diferentes tipos de solos, verificando uma redução da disponibilidade de $\mathrm{Cd}$ na presença de argila rica em fosfato. Em estudo com cinzas que continham altos teores de metais pesados provenientes de resíduos urbanos, Crannell et al. (2000) verificaram que após, aplicação de fosfato, ocorreu à redução da fração de $\mathrm{Cd}, \mathrm{Cu}$ e $\mathrm{Pb}$ no solo.

Em comparação com estudos de Oliveira e Mattiazzo (2001) e Martins et al. (2003), que encontraram diferentes padrões de acúmulo de metais pesados em plantas, foi verificado que, os efeitos de doses crescentes de lodo de 
esgoto sobre o teor de metais em cana-de-açúcar e milho apresentaram diferentes tipos de respostas, incluindo ajustes do tipo linear, assintótico e efeitos negativos ou inexistentes, em relação ao aumento dos teores de metais no solo.

Além de aumentar a adsorção e, consequentemente, diminuir a mobilidade e biodisponibilidade de $\mathrm{Cd}$ e $\mathrm{Pb}$ em solos, resíduos e outros sistemas, o P é, principalmente, usado para induzir a formação de compostos insolúveis desses metais (MA et al., 1993; CRANNELL et al., 2000). Ainda segundo Cotter-Howells e Caporn (1996) e Ma (1996), o uso de fosfatos em solos contaminados com $\mathrm{Pb}$ pode reduzir a biodisponibilidade desse elemento, graças à formação de fosfato de $\mathrm{Pb}$ (por exemplo, piromorfita).

De acordo com Santos (2007), nas duas doses de adubação utilizadas, apenas o Cd está acima do padrão estabelecido para solos, indicando, dessa forma, que houve contaminação ambiental com $\mathrm{Cd}$ no solo do experimento.

A utilização do P na redução da mobilidade de metais em áreas já contaminadas é amplamente relatada na literatura, sendo que o $\mathrm{P}$ possui a capacidade de amenizar os efeitos tóxicos de $\mathrm{Cu}, \mathrm{Pb}$ e $\mathrm{Cd}$, tanto por aumentar a adsorção, quanto por possibilitar a formação de compostos insolúveis (PIERANGELI et al., 2004; PAIM et al., 2003).

$\mathrm{Na}$ análise dos teores de $\mathrm{Zn}$ no solo (Tabela 7), observa-se que a aplicação da dose D1 não proporcionou diferença significativa entre os tratamentos de fertilização. Porém, para a dose D2, observa-se que o fertilizante B disponibilizou maior quantidade de $\mathrm{Zn}$ em relação aos demais.

Tabela 5 - Análise de variância para os teores de P, K, Ca, Mg, Zn, Pb, Cd e Cr no solo do experimento após o cultivo da soja.

\begin{tabular}{cccccccccc}
\hline \multicolumn{10}{c}{ Quadrados Médios } \\
\hline F.V. & GL & P & K & Ca & Mg & Zn & Pb & Cd & $\mathrm{Cr}$ \\
\hline Bloco & 2 & $620,50^{\mathrm{NS}}$ & $0,10^{\mathrm{NS}}$ & $0,19^{\mathrm{NS}}$ & $0,11^{\mathrm{NS}}$ & $0,18^{\mathrm{NS}}$ & $14,25^{\mathrm{NS}}$ & $0,19^{\mathrm{NS}}$ & $454,52^{\mathrm{NS}}$ \\
Dose & 1 & $6824,68^{*}$ & $2,19^{*}$ & $0,19^{\mathrm{NS}}$ & $0,41^{*}$ & $67,7^{*}$ & $354,70^{*}$ & $2,25^{*}$ & $2970,2^{*}$ \\
Fertilização. & 5 & $530,33^{\mathrm{NS}}$ & $0,05^{\mathrm{NS}}$ & $0,16^{\mathrm{NS}}$ & $0,02^{\mathrm{NS}}$ & $8,43^{*}$ & $19,99^{\mathrm{NS}}$ & $0,16^{\mathrm{NS}}$ & $151,42^{\mathrm{NS}}$ \\
DoseXFertil. & 5 & $574,42^{\mathrm{NS}}$ & $0,04^{\mathrm{NS}}$ & $0,06^{\mathrm{NS}}$ & $0,09^{\mathrm{NS}}$ & $6,68^{*}$ & $22,70^{\mathrm{NS}}$ & $0,12^{\mathrm{NS}}$ & $284,18^{\mathrm{NS}}$ \\
Resíduo & 22 & 283,32 & 0,07 & 0,15 & 0,05 & 1,26 & 42,29 & 0,22 & 191,28 \\
\hline CV $(\%)$ & - & 48,22 & 23,61 & 14,28 & 18,80 & 21,47 & 26,81 & 8,58 & 62,32 \\
\hline
\end{tabular}

* - significativo a 5\% de probabilidade, pelo teste de F (Fisher); NS - não significativo pelo teste de F (Fischer); F.V. - fonte de variação.

Tabela 6 - Valores médios dos teores de P, K, Ca, Mg, Zn, Cd, Pb e Cr, no solo, em função da dose de fertilizante.

\begin{tabular}{ccccccccc}
\hline Doses & $\mathrm{P}$ & $\mathrm{K}$ & $\mathrm{Ca}$ & $\mathrm{Mg}$ & $\mathrm{Zn}$ & $\mathrm{Cd}$ & $\mathrm{Pb}$ & $\mathrm{Cr}$ \\
\hline $\mathrm{D} 1$ & $21,13 \mathrm{~b}$ & $0,87 \mathrm{~b}$ & $2,64 \mathrm{a}$ & $1,31 \mathrm{a}$ & $3,85 \mathrm{~b}$ & $5,77 \mathrm{a}$ & $27,39 \mathrm{a}$ & $13,11 \mathrm{~b}$ \\
$\mathrm{D} 2$ & $48,67 \mathrm{a}$ & $1,37 \mathrm{a}$ & $2,79 \mathrm{a}$ & $1,10 \mathrm{~b}$ & $6,60 \mathrm{a}$ & $5,27 \mathrm{~b}$ & $21,11 \mathrm{~b}$ & $31,27 \mathrm{a}$ \\
\hline
\end{tabular}

Médias seguidas da mesma letra não diferem pelo teste de Tukey a 5\% de probabilidade; D1 - uma vez a dose; D2 - dobro da dose.

Tabela 7 - Desdobramento da interação fontes versus dose de aplicação de tratamentos com NPK+Zn sobre a análise de solo para o elemento $\mathrm{Zn}$.

\begin{tabular}{ccc}
\hline FERTILIZAÇÃO VERSUS DOSE & D1 & D2 \\
\hline Fertilizante NPK+Zn marca A & $3,7 \mathrm{Ab}$ & $6,40 \mathrm{Ba}$ \\
Fertilizante NPK+Zn marca B & $4,0 \mathrm{Ab}$ & $10,70 \mathrm{Aa}$ \\
Fertilizante NPK+Zn marca C & $3,5 \mathrm{Ab}$ & $6,56 \mathrm{Ba}$ \\
Fertilizante NPK+Zn marca D & $5,1 \mathrm{Aa}$ & $5,80 \mathrm{Ba}$ \\
Fertilizante NPK sem Zn & $2,8 \mathrm{Ab}$ & $5,10 \mathrm{Ba}$ \\
Tratamento sem NPK+Zn & $3,8 \mathrm{Aa}$ & $5,00 \mathrm{Ba}$ \\
\hline
\end{tabular}

Médias seguidas de letras iguais minúsculas na horizontal e maiúsculas na vertical, não diferem entre si pelo teste de Tukey a $5 \%$. Letras maiúsculas são referentes a fertilização para cada dose e letras minúsculas referentes as doses para cada tratamento; D1 - uma vez a dose; D2 - dobro da dose. 
Na comparação das doses dentro dos tratamentos de $\mathrm{Zn}$, observa-se que os fertilizantes formulados das marcas comerciais A, B, C, e fertilizante sem o Zn apresentaram comportamento semelhante, com médias maiores quando os tratamentos receberam o dobro da dose, sendo que ofertilizante da marca D e o tratamento sem fertilizante não apresentaram diferenças significativas para as doses utilizadas.

\section{CONCLUSÕES}

A aplicação de fertilizantes com micronutrientes mostrou efetiva disponibilização de $\mathrm{Cd}, \mathrm{Pb}$ e $\mathrm{Cr}$ para as plantas de soja e no solo utilizado, em ambas condições de adubação utilizadas.

A dose de adubação utilizada uma vez a dose de adubação proporcionou elevação da média, em relação à utilização do dobro de adubação, para os teores foliares de $\mathrm{Ca}, \mathrm{Zn}, \mathrm{Pb}, \mathrm{Cr}$ e os teores de $\mathrm{Mg}, \mathrm{Cd}$ e $\mathrm{Pb}$ no solo. Ao passo que, o dobro da adubação proporcionou elevação da média dos teores de P, K, Zn e Cr no solo.

$\mathrm{O}$ aumento dos teores de metais pesados tóxicos no solo influenciaram negativamente na absorção e acúmulo pelas plantas de soja dos nutrientes $\mathrm{Zn}$ e Ca.

\section{REFERÊNCIASBIBLIOGRÁFICAS}

AOAC. Official methods of analysis of the Association Analytical Chemists. Maryland: AOAC, 2005.3000p.

BÜLL, L.T. Nutrição mineral do milho. In: BÜLL, L. T; CANTARELLA, H. (Ed.). Cultura do milho: fatores que afetam a produtividade. Potafos, Piracicaba, p.63-145. 1993.

CARNEIRO, L.F. et al. Fontes, doses e modos de aplicação de fósforo na interação fósforo-zinco em milho. Ciência e Agrotecnologia, Lavras, v.32, n.4, p.1133-1141, jul./ago. 2008.

CHANG, A.C. et al. Effects of long term sludge application on accumulation of trace elements by crops. In: PAGE, A.L.; LOGAN, T.J.; RYAN, J.A. (Eds.). Land application of sludge: food chain implications. Lewis Publishers, Chelsea, cap.4, p.53-66. 1987.

COTTER-HOWELLS, J.; CAPORN, S. Remediation of contaminated land by formation of heavy metal phosphates. Applied Geochemistry, Penglais, v.11, n.1-2, p.335-342, jan./mar. 1996.

CRANNELL, S.B. et al. Heavy metal stabilization in municipal solid waste combustion bottom ash using soluble phosphate. Waste Manegement, v.20, p.135148. 2000.

DAVIS, R.D.; BECKETT, P.H.T.; WOLLAN, E. Critical levels of twenty potentially toxic elements in young spring barley. Plant and Soil, The Hague, v.449, n.2, p.395-408. 1978.

EMPRESA BRASILEIRA DE PESQUISA AGROPECUÁRIA. Sistema brasileiro de classificação de solos. EMBRAPA, Rio de Janeiro, 2006a. 306p.

\section{EMPRESA BRASILEIRA DE PESQUISA} AGROPECUÁRIA. Manual de métodos de análises de solo. Centro Nacional de Pesquisa de solos, $2^{\circ}$ ed. EMBRAPA, Rio de Janeiro, CNPS. 1997. 212p.

\section{EMPRESA BRASILEIRA DE PESQUISA}

AGROPECUÁRIA. Tecnologias de Produção de Soja Paraná. EMBRAPA, Londrina, 2006b. 208p.

FERREIRA. D. F. SISVAR: Sistemas de análises estatísticas. Lavras: UFLA. 2003.

GONÇALVES JUNIOR, A.C.; LUCHESE, E.B.; LENZI, E. Avaliação da fitodisponibilidade de cádmio, chumbo e crômio, em soja cultivada em latossolo vermelho escuro tratado com fertilizantes comerciais. Química Nova, São Paulo, v.23, n.2, p.173-177, mar./abr. 2000.

GONÇALVES JUNIOR et al. Produtividade e componentes de produção do milho adubado com $\mathrm{Cu}$ e NPK em um argilossolo. Scientia Agraria, Curitiba, v.9, n.1, p.35-40, jan./mar. 2008.

GONÇALVES JUNIOR et al. Produtividade e componentes de produção da soja adubada com diferentes doses de fósforo, potássio e zinco. Ciência e Agrotecnologia, Lavras, v.34, n.3, p.660666, maio/jun. 2010.

GONÇALVES JUNIOR, A.C.; PESSOA, A.C.S. Fitodisponibilidade de Cádmio, Chumbo e Crômio, em soja cultivada em argilossolo vermelho eutrófico a partir de adubos comerciais. Scientia Agrária, Curitiba, v.3, n.1-2, p.19-23, jan./dez. 2002. 
GONZALEZ, R.X.; SERTAIN, J.B.; MILLER, W.L. Cadmium availability and extractability from sewage sludge as effected by waste phosphatic clay. Journal of Environmental Quality, Stanford, v.21, n.2, p.272-275, abr./jun. 1992.

GUSSARSSON, M. et al. Cadmium and copper interactions on the accumulation and distribution of $\mathrm{Cd}$ and $\mathrm{Cu}$ in birch (Betula pendula Roth) seedlings. Plant and Soil, Dordrecht, v.171, p.185187, abr. 1995.

HUANG, J.W.; CUNNINGHAM, S.D. Lead phytoextraction: species variation in lead uptake and translocation. New Phytologist, Sheffield, v.134, n.1, p. 75-84, set. 1996.

KABATA-PENDIAS, A.; PENDIAS, H. Trace elements in soil and plants. 3.ed., Boca Raton: CRC Press, 2001. 331p.

MA, L.Q. Factors influencing the effectiveness and stability of aqueous lead immobilization by hidroxyapatite. Journal Environmental Quality, v.25, p.1420-1429. 1996.

MA, Q.Y.; TRAINA, S.J.; LOGAN, T.J. In situ lead immobilization by apatite. Environmental Science Technology, v.27, p.1803-1810. 1993.

MALAVOLTA, E.; VITTI, G.C.; OLIVEIRA, S.A. Avaliação do estado nutricional das plantas: princípios e aplicações. POTAFOS, Piracicaba. 1997. 319 p.

MARSCHNER, H. Mineral nutrition of higher plants. London: Academic Press, 1995. 889p.

MARTENS, D.C.; WESTERMANN, D.T. Fertilizers applications for correcting micronutrient deficiencies. Soil Science, Polytechnic Institute and State University, Virginia, n.4, p.549-592. 1991.

MARTINS, A.L.C. et al. Produção de grãos e absorção de $\mathrm{Cu}, \mathrm{Fe}, \mathrm{Mn}$ e $\mathrm{Zn}$ pelo milho em solo adubado com lodo de esgoto, com e sem calcário. Revista Brasileira de Ciência doSolo, Viçosa, v.27, n.3, p.563-574, mai./jun. 2003.

McBRIDE, M.B. Toxic metal accumulation from agricultural use of sludge: Are USEPA regulations protective? Journal of Environmental Qualily, v.24, p.5-18. 1995.

\section{MONTEIRO, M.F. Lixo Tóxico Vira Matéria Prima.}

Repórter Brasil, São Paulo, 17 de outubro de 2005.

Disponível em: <http://www.reporterbrasil.com.br/

exibe.php?id=171> Acesso em 15 de maio de 2009.

MORTVEDT, J.J. Adubos e adubação: Tecnologia e produção de fertilizantes com micronutrientes presença de elementos tóxicos. In: FERREIRA, M. E. et al. (Org). Micronutrientes e elementos tóxicos na agricultura. Jaboticabal: CNPq/FAPESP/POTAFOS, 2001. p.237-251.

OLIVEIRA, F.C.; MATTIAZZO, M.E. Metais pesados em Latossolo tratado com lodo de esgoto e em plantas de cana-de-açúcar. Scientia Agricola, Piracicaba, v.58, p.581-593.2001.

OLIVEIRA, I.P. et al. Concentrações residuais de cobre, ferro, manganês e zinco em Latossolo Roxo Eutrófico sob diferentes tipos de manejo. Pesquisa Agropecuária Tropical, Goiânia, v.31, n.2, p.97-103, jul./dez. 2001.

PAGE, A.L.; LOGAN, T.J.; RYAN, J.A. Land application of sludge-food chain implications. Chelsea, Lewis Publishers, 1987. 168p.

PAIM, L.A. et al. Efeito do silício e do fósforo na disponibilidade de metais pesados do solo pelo extrator mehlich. Ciência eAgrotecnologia, Lavras, v.27, n.4. 2003.

PAIVA, H.N.; CARVALHO, J.G; SIQUEIRA, J.O. Influência da aplicação de doses crescentes de chumbo sobre o teor e o conteúdo de nutrientes em mudas de cedro (Cedrela fissilis Vell.). Scientia Forestalis, Piracicaba, n.61, p.40-48, jun. 2002.

PAVAN, M.A. et al. Manual de análise química do solo e controle de qualidade. (Circular Técnica, 76). Londrina: IAPAR, 1992. 40p.

PIERANGELI, M.A.P. et al. Adsorção e dessorção de cádmio, cobre e chumbo por amostras de latossolos pré-tratadas com fósforo. Revista Brasileira de Ciência do Solo, Viçosa, v.28, n.2, p.377-384, mar./abr. 2004. 
RANGEL, O.J.P. et al. Efeito de aplicações de lodos de esgoto sobre os teores de metais pesados em folhas e grãos de milho. Revista Brasileira de Ciência do Solo, Viçosa, v30, p.583594. 2006.

SANTOS, A.D. Estudo das possibilidades de reciclagem dos resíduos de tratamento de esgoto da região Metropolitana de São Paulo. 2007. 265p.

Dissertação (Mestrado em Engenharia Civil) - Escola
Politécnica da Universidade de São Paulo, São Paulo, 2007.

WANG, Q.R. et al. Responses of legume and non-legume crop species to heavy metal in soils with multiple metal contamination. Journal of Environmental Science and Health: Part A, Philadephia, v.37, n.4, p.611-621. 2002.

WELZ, B.; SPERLING, M. Atomic Absorption

Spectrometry. Weinheim: Wiley-VHC, 1999.941p. 